\title{
rHuEPO Hyporesponsiveness and Related High Dosages Are Associated with Hyperviscosity in Maintenance Hemodialysis Patients
}

\author{
Mehtap Erkmen Uyar, ${ }^{1}$ Selami Kocak Toprak, ${ }^{2}$ Hatice Saglam, ${ }^{3}$ Emre Tutal, ${ }^{1}$ Meltem Bay, \\ Osman Ilhan, ${ }^{4}$ Zeynep Bal, ${ }^{1}$ and Siren Sezer ${ }^{1}$ \\ ${ }^{1}$ Department of Nephrology, Baskent University Medical School, 06490 Ankara, Turkey \\ ${ }^{2}$ Department of Hematology, Baskent University Medical School, 06490 Ankara, Turkey \\ ${ }^{3}$ Department of Internal Medicine, Baskent University Medical School, 06490 Ankara, Turkey \\ ${ }^{4}$ Department of Hematology, Ankara University Medical School, 06490 Ankara, Turkey
}

Correspondence should be addressed to Mehtap Erkmen Uyar; mehtap94@yahoo.com

Received 30 May 2013; Accepted 18 August 2013

Academic Editors: R. Ando, F. Hinoshita, and R. Sakai

Copyright (C) 2013 Mehtap Erkmen Uyar et al. This is an open access article distributed under the Creative Commons Attribution License, which permits unrestricted use, distribution, and reproduction in any medium, provided the original work is properly cited.

Objective. Increased viscosity may increase the risk of thrombosis or thromboembolic events. Recombinant human erythropoietin $(\mathrm{rHuEPO})$ is the key stone treatment in anemic ESRD patients with the thrombotic limiting side effect. We evaluated the influence of clinical and laboratory findings on plasma viscosity in MHD patients in the present study. Method. After applying exclusion criteria 84 eligible MHD patients were included (30 female, age: $54.7 \pm 13.7$ years). Results. Patients with high viscosity had longer MHD history, calcium $\times$ phosphorus product, and higher $\mathrm{rHuEPO}$ requirement (356.4 versus 204.2 U/kg/week, P: 0.006). rHuEPO hyporesponsiveness was also more common in hyperviscosity group. According to HD duration, no rHuEPO group had the longest and the low rHuEPO dosage group had the shortest duration. Despite similar Hb levels, $68 \%$ of patients in high rHuEPO dosage group; and $38.7 \%$ of patients in low rHuEPO dosage group had higher plasma viscosity $(P: 0.001)$. Patients with hyperviscosity had higher $\mathrm{rHuEPO} / \mathrm{Hb}$ levels $(P: 0.021)$. Binary logistic regression analyses revealed that $\mathrm{rHuEPO}$ hyporesponsiveness was the major determinant of hyperviscosity. Conclusion. We suggest that the hyperviscous state of the hemodialysis patients may arise from the inflammatory situation of long term HD, the calcium-phosphorus mineral abnormalities, rHuEPO hyporesponsiveness, and related high dosage requirements.

\section{Introduction}

The resistance of blood against blood flow is called plasma viscosity. Blood is a complex body fluid, so not only body temperature but also components of blood like hematocrit and plasma and rheological characteristics like the deformability of erythrocytes all affect plasma viscosity [1]. Plasma viscosity is influenced by diseases with altered plasma protein composition, determined by various macromolecules, for example, fibrinogen, immunoglobulin, and lipoproteins $[2,3]$. An elevated viscosity significantly increases the risk of inflammatory diseases; the strong positive correlation between plasma viscosity and fibrinogen has been reported in several studies $[2,3]$.

Chronic kidney disease (stages 4 and 5) (CKD) is also associated with alterations of coagulation that favor a hypercoagulable or prothrombotic state $[4,5]$ and thus an increased thrombotic risk that may contribute to an increase in cardiovascular morbidity and mortality [6]. In the uremic state, mechanisms including hypertension, hyperhomocysteinemia, dyslipidemia with high lipoprotein (a) (Lp(a)) levels, elevation of hemostatic derived cardiovascular risk factors (fibrinogen and proconvertin) [6], and amplification of the inflammatory cascade at the endothelial cell (growth factors, 
cytokines, and adhesion molecules) [7] are activated [8]. The characteristic of blood flow is closely related to the blood flow circumstances with all the factors above as seen in atherosclerotic diseases [9].

Elevated plasma viscosity results in greater flow resistance and a high incidence of circulatory complications [10]. Increased blood and plasma viscosity has been described in patients with coronary and peripheral arterial disease. An increase in factor VII plasma levels, hematocrit, and platelet function [11-13] and a decrease in anticoagulant protein S, C, and antithrombin III [14, 15] have been described in ESRD. Increased viscosity may increase the risk of thrombosis or thromboembolic events [16].

In ESRD patients the limiting side effect of recombinant human erythropoietin (rHuEPO) is the thrombotic side effect. Several reports have associated long-term rHuEPO treatment with thrombotic complications of arteriovenous fistulae, convulsion and cerebrovascular disease, hyperviscosity, and hypertension [17-21]. In patients undergoing dialysis, the risk of death has been shown to be inversely associated with a good hematopoietic response to $\mathrm{rHuEPO}$ [22]. It has specifically been shown in the TREAT cohort that poor hemoglobin response to ESA treatment is associated with poor outcomes [23]. The patients with the poorest initial response received the highest average doses of ESAs and had the highest event rates [24]. Also the weak association between a poor initial response and the C-reactive protein level also suggests that inflammatory factors may contribute to a poor initial response [25]. Normal hemoglobin levels in patients without $\mathrm{rHuEPO}$ usage had no influence on mortality [25].

In the light of all these data, we planned to evaluate the influence of clinical and laboratory findings including iron parameters, hemoglobin, albumin, CRP, parathyroid hormone, and monthly rHuEPO requirements on plasma viscosity in maintenance hemodialysis (MHD) patients in this present study.

\section{Patients and Methods}

258 ESRD patients receiving MHD in our hemodialysis unit for at least 12 months were prospectively analyzed for 12 months. Patients who had active infection, iron deficiency (ferritin levels $<200 \mathrm{mg} / \mathrm{dL}$ or transferrin saturation $<20 \%$ ), malignancy, severe clinical malnutrition, receiving antiaggregant, or anticoagulant therapy (except intradialytic heparinization) were excluded. After applying exclusion criteria 84 eligible patients were included (30 female, age: $54.7 \pm 13.7$ years). Informed consent was obtained in each patient. Plasma viscosity was studied in a fasting blood sample which was sampled just before a clinically stable HD session. Plasma viscosities of all subjects were measured at $37^{\circ} \mathrm{C}$ in a Brookfield DV-II + Clone Plate Viscometer [Brookfield, Stoughton, MA, USA]. Data including iron parameters and treatment dosage, hemoglobin, albumin, CRP, calcium, phosphorus, parathyroid hormone, and monthly rHuEPO requirement were collected from patient charts and a mean value of the 12 months follow-up period was recorded as the final data. Patients' thromboembolic events like myocardial infarction, cerebrovascular disease, deep venous thrombosis and pulmonary thromboembolism, and arteriovenous fistula complications (like thrombus, emboli, or clotting) were analyzed and recorded in the one-year followup.

Study group was divided into two equal sized groups as high ( $n: 42)$ and low viscosity groups ( $n$ : 42$)$ for statistical analysis. Then these two groups were compared with each other in means of demographical and biochemical characteristics. $\mathrm{rHuEPO}$ hyporesponsiveness was defined as $\mathrm{rHuEPO}$ requirements $>150 \mathrm{U} / \mathrm{kg} /$ week to achieve a target hemoglobin level of 11-12 g/dL. We classified patients receiving $\mathrm{rHuEPO}$ (>150 U/kg/week) as hyporesponsive ( $n$ : 40$)$, low dose rHuEPO (75-300 U/kg/week) (n: 23), and no rHuEPO (n: 21) groups.

2.1. Statistical Analysis. Statistical analyses were performed by using SPSS software (Statistical Package for the Social Sciences, version 11.0, SSPS Inc., Chicago, IL, USA). Normality of data was analyzed by using a Kolmogorov-Smirnov test. All numerical variables with normal distribution were expressed as the means \pm standard deviations $(\mathrm{SD})$, while variables with skew distribution were expressed as medians and interquartile range (IR). Categorical variables were expressed as percentages and compared by chi-square test. Normally distributed numeric variables were analyzed by independent samples $t$ - or one-way ANOVA (post hoc Tukey) tests according to distribution normality. Skew distributed numeric variables were compared using the Mann-Whitney $U$ and Kruskal-Wallis tests according to distribution normality. Spearman and Pearson Correlation tests were used for correlation analyses. A $P$ value $<0.05$ was considered as statistically significant.

\section{Results}

Demographic and biochemical characteristics of study groups are summarized in Table 1. Plasma viscosity of whole study group was $2.52 \pm 0.65$ (range 1.6-3.9) mPas. Plasma viscosity was positively correlated with duration of $\mathrm{MHD}$ ( $r$ : 0.287, P: 0.008, Figure 1). Comparison of high and low viscosity groups revealed that patients with high viscosity had longer MHD history (133.2 \pm 77.1 versus $97.5 \pm 83.1$ months, $P$ : 0.044), higher calcium $(9.51 \pm 0.61$ versus $9.13 \pm 0.65 \mathrm{mg} / \mathrm{dL}$, $P: 0.009)$, phosphorus $(5.18 \pm 0.8$ versus $4.71 \pm 1.09 \mathrm{mg} / \mathrm{dL}$, $P: 0.035)$, calcium $\times$ phosphorus product $(49.37 \pm 9.39$ versus $43.45 \pm 11.4, P: 0.011)$, and higher $\mathrm{rHuEPO}$ requirement (356.4 (295.7) versus 204.2 (350.8) U/kg/week, P: 0.006 , Table 2). rHuEPO hyporesponsiveness was also more common in hyperviscosity group (28/42, $66.7 \%$ versus $13 / 42,31 \%$, $P: 0.004)$. those of Patients with hyperviscosity had higher $\mathrm{rHuEPO} / \mathrm{Hb}$ levels ( $P: 0.021$ ). In hyperviscosity group the $\mathrm{rHuEPO}$ requirements of patients were higher $(28 / 42,66.7 \%$ versus $13 / 42,31 \%, P: 0.004)$ than patients having lower viscosity.

According to the one-year follow-up data of the patients, thromboembolic complications of arteriovenous fistula were significantly higher in patients with hyperviscosity in than 
TABLE 1: Demographic and biochemical characteristics of the whole study group.

\begin{tabular}{lc}
\hline & Study group $(n=84)$ \\
\hline Age (years) & $54.88 \pm 13.7$ \\
Gender (F/M) & $30 / 54$ \\
Mean plasma viscosity (mPas) & $2.52 \pm 0.65$ \\
MHD duration (months) & $115.41 \pm 81.72$ \\
Mean serum Hb level (g/dL) & $11.28 \pm 1.53$ \\
Mean serum WBC count $(/ \mu \mathrm{L})$ & $7.40 \pm 1.84$ \\
Mean serum Plt count $(/ \mu \mathrm{L})$ & $215.89 \pm 64.35$ \\
Median serum PTH level $(\mathrm{pg} / \mathrm{mL})$ & $397.85(498.30)$ \\
Mean serum Ca level $(\mathrm{mg} / \mathrm{dL})$ & $9.31 \pm 0.65$ \\
Mean serum P level $(\mathrm{mg} / \mathrm{dL})$ & $4.95 \pm 1.00$ \\
Mean Ca $\times$ P product & $46.41 \pm 10.80$ \\
Mean serum CRP level $(\mathrm{mg} / \mathrm{L})$ & $16.28 \pm 11.28$ \\
Mean serum albumin level $(\mathrm{g} / \mathrm{dL})$ & $3.64 \pm 0.35$ \\
Median serum ferritin level $(\mathrm{ng} / \mathrm{mL})$ & $531.00(331.50)$ \\
Total parenteral iron therapy $(\mathrm{U} / 12$ months) & $20000(3000)$ \\
Total rHuEPO usage $(\mathrm{U} / \mathrm{kg} / \mathrm{week})$ & $295.00(422.35)$ \\
rHuEPO/Hb & $25.49 \pm 20.48$ \\
\hline
\end{tabular}

patients with lower viscosity (54.8\% versus $36.3 \%, P$ : 0.023$)$. Other thromboembolic events like myocardial infarction, cerebrovascular disease, deep venous thrombosis, pulmonary thromboembolism, and mortality rates were similar between the two groups (Table 3). Acute myocardial infarction, pulmonary thromboembolism, and mortality rates were also not significant but higher in hyperviscosity group (Table 3 ).

Plasma viscosity of patients with no rHuEPO group ( $n=$ $21)$, low rHuEPO dosage group $(n=31)$, and high $\mathrm{rHuEPO}$ dosage group $(n=32)$, was $2.5 \pm 0.6,2.4 \pm 0.7$ and $2.6 \pm 0.5$, respectively $(P>0.05)$. The clinical and biochemical characteristics of rHuEPO user and nonuser patients are summarized in Table 4 . In the three groups, there was no statistically significant difference in plasma viscosity of patients between different $\mathrm{Hb}$ levels $(P>0.05)$. Despite similar $\mathrm{Hb}$ levels (11-12 g/dL), 68\% of patients in high rHuEPO dosage group and $38.7 \%$ of patients in low rHuEPO dosage group had higher plasma viscosity ( $P: 0.001)$. According to HD duration, no rHuEPO group had the longest and the low $\mathrm{rHuEPO}$ dosage group had the shortest HD duration.

Binary logistic regression analyses revealed that $\mathrm{rHuEPO}$ hyporesponsiveness was the major determinant of hyperviscosity $(P: 0.001)$.

\section{Discussion}

Hyperviscosity has effects leading to atherosclerosis, and its negative impact on atherosclerosis was found to be more intense than that of the traditional risk factors [26, 27]. Increased viscosity also has negative impact on vascular structure. Yarnell et al. found that in a population of 4860 men, death, acute myocardial infraction, and urgent cardiovascular surgery requirement were significantly higher in hyperviscosity group than in patients with lower blood

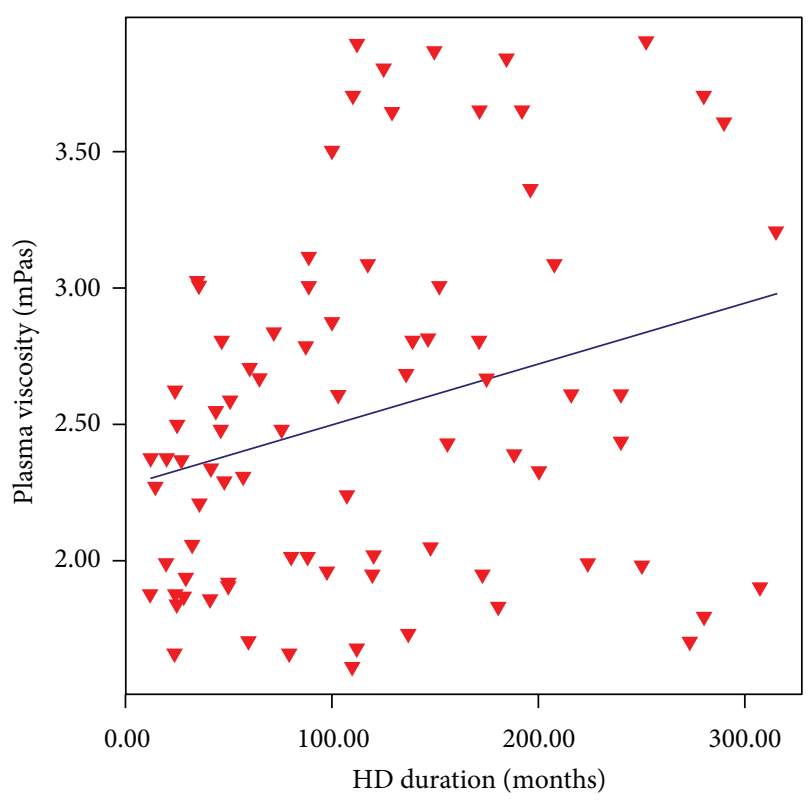

FIGURE 1: Plasma viscosity was positively correlated with patients' hemodialysis duration $(r: 0.287, P: 0.008)$.

viscosity [28]. On the other hand traditional cardiovascular risk factors like hypertension, obesity, smoking, high LDLcholesterol levels and diabetes are also known to cause hyperviscosity [29-31]. Therefore, the interaction between blood viscosity and cardiovascular risk factors is complex but undeniable [32].

Survival of ESRD patients is significantly lower than that of normal population. Factors associated with increased mortality in ESRD were extensively studied and some significant factors like chronic inflammation, malnutrition, hyperphosphatemia, increased calcium $\times$ phosphorus product levels, and severe anemia are already defined as factors associated with all-cause and atherosclerosis related mortality [33-38]. In a study by Suzuki et al., the severity of atherosclerosis in maintenance hemodialysis patients was dependent on age and $\mathrm{HD}$, gender, dyslipidemia, smoking, $\mathrm{HD}$ therapy, and $\mathrm{HD}$ duration [39].

In this study, we found higher plasma viscosity levels in ESRD patients undergoing MHD than that in normal population. We also found longer MHD duration, higher calcium, phosphorus, calcium $\times$ phosphorus product values, and higher dose rHuEPO requirement in patients with high viscosity. rHuEPO hyporesponsiveness was also more common in hyperviscosity group as for similar $\mathrm{Hb}$ levels higher dosage $\mathrm{rHuEPO}$ were required in this group. Longer $\mathrm{HD}$ duration and high dosage $\mathrm{rHuEPO}$ usage due to $\mathrm{rHuEPO}$ hyporesponsiveness were the major determinants of hyperviscosity.

In chronic kidney disease, serum calcium and especially phosphorus levels have been associated with vascular calcification and atherosclerosis [40]. Studies have shown a correlation between elevated phosphorus levels in dialysis and mortality [41]. Phosphorus has been shown to be an independent risk factor for cardiovascular disease 
TABLE 2: Demographic and biochemical characteristics of the study groups.

\begin{tabular}{|c|c|c|c|}
\hline & $\begin{array}{l}\text { Group } 1(n=42) \\
\text { (lower viscosity) }\end{array}$ & $\begin{array}{c}\text { Group } 2(n=42) \\
\text { (hyperviscosity) }\end{array}$ & $P$ value \\
\hline Age & $55.4 \pm 14.8$ & $54.3 \pm 12.5$ & 0.728 \\
\hline HD duration (months) & $97.5 \pm 83.1$ & $133.2 \pm 77.1$ & 0.044 \\
\hline PTH $(\mathrm{pg} / \mathrm{mL})$ & $492.3 \pm 500.3$ & $562 \pm 436$ & 0.498 \\
\hline Calcium (Ca) (mg/dL) & $9.1 \pm 0.6$ & $9.5 \pm 0.6$ & 0.009 \\
\hline Phosphor (P) (mg/dL) & $4.7 \pm 1$ & $5.1 \pm 0.8$ & 0.035 \\
\hline $\mathrm{Ca} \times \mathrm{P}$ & $43.4 \pm 11.4$ & $49.3 \pm 9.3$ & 0.011 \\
\hline Albumin (g/dL) & $3.7 \pm 0.3$ & $3.5 \pm 0.3$ & 0.171 \\
\hline URR (\%) & $69.4 \pm 5.8$ & $71.7 \pm 6.1$ & 0.079 \\
\hline $\mathrm{Hb}(\mathrm{g} / \mathrm{dL})$ & $11.4 \pm 1.7$ & $11.1 \pm 1.3$ & 0.439 \\
\hline Platelet $(/ \mu \mathrm{L})$ & $221.8 \pm 66.4$ & $209.7 \pm 62.3$ & 0.396 \\
\hline CRP (mg/L) & $16.7 \pm 11.4$ & $15.8 \pm 11.2$ & 0.735 \\
\hline Gender $(\mathrm{F} / \mathrm{M})$ & $12 / 32$ & $18 / 24$ & 0.255 \\
\hline Need of rHuEPO usage for Hb 11-12 g/dL (\%) & 31 & 66.7 & 0.004 \\
\hline rHuEPO dosage (U/kg/week) & $204.2(350.8)$ & $356.4(295.7)$ & 0.006 \\
\hline $\mathrm{rHuEPO} / \mathrm{Hb}$ & $20.39 \pm 19.83$ & $30.71 \pm 20.04$ & 0.021 \\
\hline
\end{tabular}

TABLE 3: Thrombotic complications and mortality of the study groups.

\begin{tabular}{lccc}
\hline & $\begin{array}{c}\text { Group 1 } \\
(n=42) \\
\text { (lower viscosity) }\end{array}$ & $\begin{array}{c}\text { Group 2 } \\
(n=42) \\
\text { (hyperviscosity) }\end{array}$ & $P$ value \\
\hline $\begin{array}{l}\text { Thrombotic AVF } \\
\text { complications }(n, \%)\end{array}$ & $13,30.9 \%$ & $23,54.7 \%$ & 0.023 \\
$\begin{array}{l}\text { Acute myocardial } \\
\text { infarction }(n, \%)\end{array}$ & $8,19 \%$ & $13,30.9 \%$ & 0.208 \\
$\begin{array}{l}\text { Deep venous } \\
\text { thrombosis }(n, \%)\end{array}$ & $2,4.7 \%$ & 0 & 0.152 \\
$\begin{array}{l}\text { Pulmonary } \\
\text { thromboembolism } \\
(n, \%)\end{array}$ & 0 & $1,2.38 \%$ & 0.314 \\
$\begin{array}{l}\text { Cerebrovascular } \\
\text { disease }(n, \%)\end{array}$ & $2,4.7 \%$ & $1,2.38 \%$ & 0.557 \\
Mortality $(n, \%)$ & $3,7.1 \%$ & $5,11.9 \%$ & 0.457 \\
\hline
\end{tabular}

[42], including increased intima media thickness [43-45], vessel stiffness [46,47], and left ventricular hypertrophy [44]; PTH per se may contribute to vascular injury via mechanisms other than its effect on calcium-phosphorus homeostasis [48]. In previous studies, a strong correlation between higher rates of vascular calcification, cardiovascular mortality, and malnutrition and endothelial dysfunction and inflammation states were found in dialysis patients [49-51]. Serum fetuin-A levels, as both a calcification inhibitor protein and a negative acute-phase reactant, are significantly lower in dialysis patients and results of these studies suggest a link between inflammation and atherosclerosis in these patients [49-51]. In this present study, patients with high viscosity levels were found to have higher calcium, phosphorus, and calcium $\times$ phosphorus product values but similar CRP levels (mean $16.28 \pm 11.28 \mathrm{mg} / \mathrm{dL}$ ) when compared to low viscosity group. We suggest that long HD duration and high calcium and phosphorus levels leading endothelial dysfunction and microinflammation may cause hyperviscosity, thus increased thrombogenicity and atherosclerotic lesions.

Iron deficiency can increase the number of platelets in blood, which is linked with a hypercoagulable state [52]. As serum iron is an important regulator of thrombopoiesis and normal iron levels are required to prevent thrombocytosis by acting as an inhibitor [53], we selected patients with normal iron parameters.

Although anemia has been associated with increased rates of death and complications in patients with chronic or end stage kidney disease $[54,55]$ a reduced hematopoietic response to ESAs has also been associated with an increased risk of an adverse outcome [56-60]. It has been shown in the TREAT cohort that the patients with the poorest initial response to ESA treatment received the highest average doses of ESAs and had the highest event rates and the poor outcome [23]. Of note, a higher rate of increase in the hemoglobin level was not associated with greater risk. Indeed, patients with the greatest increase in hemoglobin level during the initial month of therapy had the lowest risk of clinical events [24]. In our study, higher dosage of $\mathrm{rHuEPO}$ was required for similar $\mathrm{Hb}$ levels in hyperviscosity group without iron deficiency.

Higher ESA requirements may lead to an increased risk for adverse outcomes due to the underlying factors affecting rHuEPO response, such as inflammation, and the potential nonerythropoietic effects of greater administered ESA doses $[23,61,62]$. However, the pathway inducing inflammationmediated EPO resistance has not been determined [63]. The inflammatory cytokines are in turn thought to directly inhibit erythropoiesis and promote apoptosis of erythroid precursors $[64,65]$. In our study, the serum CRP levels of both groups with high and low viscosity were similar and slightly 
TABle 4: Demographic and biochemical characteristics of the study groups.

\begin{tabular}{lccc}
\hline & $\begin{array}{c}\text { Patients with no } \\
\text { rHuEPO }(n=21)\end{array}$ & $\begin{array}{c}\text { Patients with low dose } \\
\text { rHuEPO }(n=31)\end{array}$ & $\begin{array}{c}\text { Patients with high } \\
\text { dose rHuEPO }(n=32)\end{array}$ \\
\hline Age (years) & $54.3 \pm 8.9$ & $57.6 \pm 17.4$ & $53.5 \pm 13.4$ \\
Mean plasma viscosity (mPas) & $2.5 \pm 0.6$ & $2.4 \pm 0.7$ & $2.6 \pm 0.5$ \\
MHD duration (months) & $141.3 \pm 87.6$ & $83.7 \pm 79.8$ & $120.0 \pm 75.5$ \\
Mean serum Hb level (g/dL) & $13.1 \pm 1.1$ & $10.7 \pm 1.06$ & $10.5 \pm 1.02$ \\
Mean serum Plt count $(/ \mu \mathrm{L})$ & $216.4 \pm 60.4$ & $209.7 \pm 59.5$ & $219.2 \pm 70.1$ \\
Median serum PTH level $(\mathrm{pg} / \mathrm{mL})$ & $409.5 \pm 372.07$ & $422.4 \pm 359.8$ & $649.2 \pm 540.7$ \\
Mean serum Ca level $(\mathrm{mg} / \mathrm{dL})$ & $9.3 \pm 0.4$ & $9.1 \pm 0.7$ & $9.4 \pm 0.6$ \\
Mean serum P level (mg/dL) & $4.8 \pm 0.8$ & $4.6 \pm 1.03$ & $5.1 \pm 1.02$ \\
Mean serum CRP level & $12.4 \pm 11.6$ & $18.08 \pm 10.03$ & $17.2 \pm 11.5$ \\
Mean serum albumin level (g/dL) & $3.7 \pm 0.2$ & $3.6 \pm 0.3$ & $3.6 \pm 0.4$ \\
Total parenteral iron therapy (U/12 months) & $2523.8 \pm 1141.4$ & $2231.3 \pm 1079.2$ & $2278.3 \pm 1644.5$ \\
Mean URR (\%) & $68.5 \pm 5.6$ & $70.1 \pm 6.6$ & $71.9 \pm 5.8$ \\
\hline
\end{tabular}

increased; the rHuEPO hyporesponsiveness in high viscosity group was not associated with clinically evident inflammation. We suggest microinflammation due to increased cytokine production as a result of comorbidity [such as heart failure, atherosclerosis, and volume overload], accumulation of advanced glycation end products, carbonyl stress, and oxidative stress could influence both viscosity and rHuEPO resistance.

In this present study, the frequency of thromboembolic complications of arteriovenous fistula [AVF] was significantly higher in patients with hyperviscosity. Vascular access failure is a major contributor to the morbidity and mortality of hemodialysis patients $[66,67]$. AVF prevention and management of its complications remain the safest and most comfortable solution to ensure AVF survival and thus a satisfying survival and quality of life in MHD patients [68]. Regression analyses of our study revealed that $\mathrm{rHuEPO}$ hyporesponsiveness was the major determinant of hyperviscosity; therefore we strongly suggest that higher EPO dosage need in MHD may predispose thromboembolic events of AVF. Hyperviscosity seems to play a key role for thromboembolic AVF complications of rHuEPO hyporesponsiveness.

\section{Conclusion}

In conclusion, according to our findings we suggest that the hyperviscous state of the hemodialysis patients may arise mostly from the inflammatory situation of long-term HD, the calcium-phoshorus mineral abnormalities and rHuEPO hyporesponsiveness and related high dosage requirements. Hyperviscosity seems to play a critical role for the thrombotic side effects of rHuEPO and not hemoglobin levels but high serum viscosity level is probably associated with high serum calcium-phosphorus levels, endothelial dysfunction, and vascular calcification. Therapies targeting hyperviscosity may reduce cardiovascular complications of the hemodialysis patients. Further prospective studies with long-term followup are needed to show the exact mechanisms of hyperviscosity in hemodialysis patients.

\section{Conflict of Interests}

The authors declare that there is no conflict of interests.

\section{References}

[1] A. Yonem, B. Cakir, O. Azal et al., "Blood viscosity and its relationship with plasma fibrinogen and cholesterol levels in young obese patients," Turkish Medical Journal, vol. 6, no. 6, pp. 295-298, 1999.

[2] F. Jung, G. Pindur, and H. Kiesewetter, "Plasma viscosity dependence on proteins and lipoprotiens: results of the Aachen study," Clinical Hemorheology, vol. 12, no. 4, pp. 557-571, 1992.

[3] W. Koenig, M. Sund, B. Filipiak, A. Döring, H. Löwel, and E. Ernst, "Plasma viscosity and the risk of coronary heart disease: results from the MONICA-Augsburg cohort study, 1984 to 1992," Arteriosclerosis, Thrombosis, and Vascular Biology, vol. 18, no. 5, pp. 768-772, 1998.

[4] D. Molino, D. De Lucia, and N. G. De Santo, "Coagulation disorders in uremia," Seminars in Nephrology, vol. 26, no. 1, pp. 46-51, 2006.

[5] P. M. Ambühl, R. P. Wüthrich, W. Korte, L. Schmid, and R. Krapf, "Plasma hypercoagulability in haemodialysis patients: impact of dialysis and anticoagulation," Nephrology Dialysis Transplantation, vol. 12, no. 11, pp. 2355-2364, 1997.

[6] J.-C. Gris, B. Branger, F. Vécina, B. Al Sabadani, J. Fourcade, and J.-F. Schved, "Increased cardiovascular risk factors and features of endothelial activation and dysfunction in dialyzed uremic patients," Kidney International, vol. 46, no. 3, pp. 807-813, 1994.

[7] N. Ferrara and S. Bunting, "Vascular endothelial growth factor, a specific regulator of angiogenesis," Current Opinion in Nephrology and Hypertension, vol. 5, no. 1, pp. 35-44, 1996.

[8] A. Aguilera, M. A. Bajo, J. J. Díez et al., "Effects of human recombinant erythropoietin on inflammatory status in peritoneal dialysis patients," Advances in Peritoneal Dialysis, vol. 18, pp. 200-205, 2002.

[9] G. D. O. Lowe, "Blood viscosity and cardiovascular disease," Thrombosis and Haemostasis, vol. 67, no. 5, pp. 494-498, 1992.

[10] D. E. McMillan, "Physical factors important in the development of atherosclerosis in diabetes," Diabetes, vol. 30, no. 2, pp. 97$104,1981$. 
[11] A. B. Irish and F. R. Green, "Factor VII coagulant activity (VIIc) and hypercoagulability in chronic renal disease and dialysis: relationship with dyslipidaemia, inflammation, and factor VII genotype," Nephrology Dialysis Transplantation, vol. 13, no. 3, pp. 679-684, 1998.

[12] J. Stasko, S. Funiak, S. Funiakova et al., "Erythropoietin, thrombomodulin, factor von Willebrand and hemodialysis," Revista Iberoamericana de Trombosis y Hemostasia, vol. 8, article 134, 1995.

[13] J. J. J. M. Wirtz, J. W. J. Van Esser, K. Hamulyak, K. M. L. Leunissen, and J. P. Van Hooff, "The effects of recombinant human erythropoietin on hemostasis and fibrinolysis in hemodialysis patients," Clinical Nephrology, vol. 38, no. 5, pp. 277-282, 1992.

[14] B. Jaar, A. Denis, B. Viron et al., "Effects of long-term treatment with recombinant human erythropoietin on physiologic inhibitors of coagulation," American Journal of Nephrology, vol. 17, no. 5, pp. 399-405, 1997.

[15] T. Arinsoy, O. Ozdemir, N. Arik et al., "Recombinant human erythropoietin treatment may induce antithrombin-III depletion," Nephron, vol. 62, no. 4, pp. 480-481, 1992.

[16] C.-H. Ho, "White blood cell and platelet counts could affect whole blood viscosity," Journal of the Chinese Medical Association, vol. 67, no. 8, pp. 394-397, 2004.

[17] M. R. W. Langenfeld, R. Veelken, H. P. Schobel, A. Friedrich, and R. E. Schmieder, "Is endogenous erythropoietin a pathogenetic factor in the development of essential hypertension?" Nephrology Dialysis Transplantation, vol. 12, no. 6, pp. 1155-1160, 1997.

[18] I. C. MacDougall, M. E. Davies, I. Hallett, D. L. Cochlin, R. D. Hutton, and G. A. J. D. Coles Williams, "Coagulation studies and fistula blood flow during Erythropoitin therapy in haemodialysis patients," Nephrology Dialysis Transplantation, vol. 6, no. 11, pp. 862-867, 1991.

[19] A. E. G. Raine, "Hypertension, blood viscosity, and cardiovascular morbidity in renal failure: implications of erythropoietin therapy," The Lancet, vol. 1, no. 8577, pp. 97-99, 1988.

[20] G. R. Dy, E. J. Bloom, G. K. Ijelu, G. W. Merritts, M. S. Kramer, and R. M. Raja, "Effect of recombinant human erythropoietin on vascular access," ASAIO Transactions, vol. 37, no. 3, pp. M274-M275, 1991.

[21] N. Muirhead, "Erythropoietin is a cause of access thrombosis," Seminars in Dialysis, vol. 6, pp. 184-188, 1993.

[22] B. D. Bradbury, M. D. Danese, M. Gleeson, and C. W. Critchlow, "Effect of epoetin alfa dose changes on hemoglobin and mortality in hemodialysis patients with hemoglobin levels persistently below $11 \mathrm{~g} / \mathrm{dL}$," Clinical Journal of the American Society of Nephrology, vol. 4, no. 3, pp. 630-637, 2009.

[23] S. D. Solomon, H. Uno, E. F. Lewis et al., "Erythropoietic response and outcomes in kidney disease and type 2 diabetes," The New England Journal of Medicine, vol. 363, no. 12, pp. 1146$1155,2010$.

[24] E. F. Unger, A. M. Thompson, M. J. Blank, and R. Temple, "Erythropoiesis-stimulating agents-time for a reevaluation," The New England Journal of Medicine, vol. 362, no. 3, pp. 189192, 2010.

[25] S. D. Solomon, H. Uno, E. F. Lewis et al., "Erythropoietic response and outcomes in kidney disease and type 2 diabetes. Trial to Reduce Cardiovascular Events with Aranesp Therapy [TREAT] Investigators," The New England Journal of Medicine, vol. 363, no. 12, pp. 1146-1155, 2010.

[26] K. R. Kensey, "The mechanistic relationships between hemorheological characteristics and cardiovascular disease," Current Medical Research and Opinion, vol. 19, no. 7, pp. 587-596, 2003.
[27] A. J. Lee, P. I. Mowbray, G. D. O. Lowe, A. Rumley, F. G. R. Fowkes, and P. L. Allan, "Blood viscosity and elevated carotid intima-media thickness in men and women: the Edinburgh Artery Study," Circulation, vol. 97, no. 15, pp. 1467-1473, 1998.

[28] J. W. G. Yarnell, I. A. Baker, P. M. Sweetnam et al., "Fibrinogen, viscosity, and white blood cell count are major risk factors for ischemic heart disease. The Caerphilly and Speedwell collaborative heart disease studies," Circulation, vol. 83, no. 3, pp. 836-844, 1991.

[29] L. Bogar, "Hemorheology and hypertension: not "chicken or egg" but two chickens from similar eggs," Clinical Hemorheology and Microcirculation, vol. 26, no. 2, pp. 81-83, 2002.

[30] M. W. Rampling, "Haemorheological disturbances in hypertension: the influence of diabetes and smoking," Clinical Hemorheology and Microcirculation, vol. 21, no. 3-4, pp. 183-187, 1999.

[31] G. De Simone, R. B. Devereux, S. Chien, M. H. Alderman, S. A. Atlas, and J. H. Laragh, "Relation of blood viscosity to demographic and physiologic variables and to cardiovascular risk factors in apparently normal adults," Circulation, vol. 81, no. 1, pp. 107-117, 1990.

[32] N. Dikmenoglu, "Kardiyovasküler hastalıklarda sigara ve kolesterol kadar önemli bir risk faktörü: kan akıskanlıg1," Hacettepe Tıp Dergisi, vol. 37, pp. 93-97, 2006.

[33] K. Ateş, G. Nergizoğlu, K. Keven et al., "Effect of fluid and sodium removal on mortality in peritoneal dialysis patients," Kidney International, vol. 60, no. 2, pp. 767-776, 2001.

[34] A. H. Tzamaloukas, M. C. Saddler, G. H. Murata et al., "Symptomatic fluid retention in patients on continuous peritoneal dialysis," Journal of the American Society of Nephrology, vol. 6, no. 2, pp. 198-206, 1995.

[35] C. H. Jones, C. G. Newstead, E. J. Wills, and A. M. Davison, "Serum albumin and survival in CAPD patients: the implications of concentration trends over time," Nephrology Dialysis Transplantation, vol. 12, no. 3, pp. 554-558, 1997.

[36] P. G. Blake, G. Flowerdew, R. M. Blake, and D. G. Oreopoulos, "Serum albumin in patients on continuous ambulatory peritoneal dialysis-predictors and correlations with outcomes," Journal of the American Society of Nephrology, vol. 3, no. 8, pp. 1501-1507, 1993.

[37] S. H. Chung, B. Lindholm, and H. B. Lee, "Is malnutrition an independent predictor of mortality in peritoneal dialysis patients?" Nephrology Dialysis Transplantation, vol. 18, no. 10, pp. 2134-2140, 2003.

[38] H. Noh, S. W. Lee, S. W. Kang et al., "Serum C-reactive protein: a predictor of mortality in continuous ambulatory peritoneal dialysis patients," Peritoneal Dialysis International, vol. 18, no. 4, pp. 387-394, 1998.

[39] C. Suzuki, S. Nakamura, H. Ishibashi-Ueda, F. Yoshihara, and Y. Kawano, "Evidence for severe atherosclerotic changes in chronic hemodialysis patients: comparative autopsy study against cardiovascular disease patients without chronic kidney disease," Therapeutic Apheresis and Dialysis, vol. 15, no. 1, pp. 5157, 2011.

[40] K. L. Adeney, D. S. Siscovick, J. H. Ix et al., "Association of serum phosphate with vascular and valvular calcification in moderate CKD," Journal of the American Society of Nephrology, vol. 20, no. 2, pp. 381-387, 2009.

[41] W. Y. Qunibi, "Consequences of hyperphosphatemia in patients with end-stage renal disease (ESRD)," Kidney International, Supplement, vol. 66, no. 90, pp. S8-S12, 2004.

[42] G. A. Block, T. E. Hulbert-Shearon, N. W. Levin, and F. K. Port, "Association of serum phosphorus and calcium $\mathrm{x}$ phosphate 
product with mortality risk in chronic hemodialysis patients: a national study," American Journal of Kidney Diseases, vol. 31, no. 4, pp. 607-617, 1998.

[43] M. Litwin, E. Wühl, C. Jourdan et al., "Altered morphologic properties of large arteries in children with chronic renal failure and after renal transplantation," Journal of the American Society of Nephrology, vol. 16, no. 5, pp. 1494-1500, 2005.

[44] M. M. Mitsnefes, T. R. Kimball, J. Kartal et al., "Cardiac and vascular adaptation in pediatric patients with chronic kidney disease: role of calcium-phosphorus metabolism," Journal of the American Society of Nephrology, vol. 16, no. 9, pp. 2796-2803, 2005.

[45] A. Saygili, Ö. Barutçu, N. Cengiz et al., "Carotid intima media thickness and left ventricular changes in children with endstage renal disease," Transplantation Proceedings, vol. 34, no. 6, pp. 2073-2075, 2002.

[46] A. Covic, N. Mardare, P. Gusbeth-Tatomir et al., "Increased arterial stiffness in children on haemodialysis," Nephrology Dialysis Transplantation, vol. 21, no. 3, pp. 729-735, 2006.

[47] J. Blacher, M. E. Safar, A. P. Guerin, B. Pannier, S. J. Marchais, and G. M. London, "Aortic pulse wave velocity index and mortality in end-stage renal disease," Kidney International, vol. 63, no. 5, pp. 1852-1860, 2003.

[48] R. C. Shroff, A. E. Donald, M. P. Hiorns et al., "Mineral metabolism and vascular damage in children on dialysis," Journal of the American Society of Nephrology, vol. 18, no. 11, pp. 2996-3003, 2007.

[49] M. Ketteler, P. Bongartz, R. Westenfeld et al., "Association of low fetuin-A (AHSG) concentrations in serum with cardiovascular mortality in patients on dialysis: a cross-sectional study," The Lancet, vol. 361, no. 9360, pp. 827-833, 2003.

[50] H. Honda, A. R. Qureshi, O. Heimbürger et al., "Serum albumin, C-reactive protein, interleukin 6, and fetuin a as predictors of malnutrition, cardiovascular disease, and mortality in patients with ESRD," American Journal of Kidney Diseases, vol. 47, no. 1, pp. 139-148, 2006.

[51] P. Stenvinkel, K. Wang, A. R. Qureshi et al., "Low fetuin-A levels are associated with cardiovascular death: impact of variations in the gene encoding fetuin," Kidney International, vol. 67, no. 6, pp. 2383-2392, 2005.

[52] N. Nicastro, A. Schnider, and B. Leemann, "Iron-deficiency anemia as a rare cause of cerebral venous thrombosis and pulmonary embolism," Case Reports in Medicine, vol. 2012, Article ID 497814, 3 pages, 2012.

[53] D. S. Hartfield, N. J. Lowry, D. L. Keene, and J. Y. Yager, "Iron deficiency: a cause of stroke in infants and children," Pediatric Neurology, vol. 16, no. 1, pp. 50-53, 1997.

[54] F. Locatelli, R. L. Pisoni, C. Combe et al., "Anaemia in haemodialysis patients of five European countries: association with morbidity and mortality in the Dialysis Outcomes and Practice Patterns Study (DOPPS)," Nephrology Dialysis Transplantation, vol. 19, no. 6, pp. 121-132, 2004.

[55] P. T. Vlagopoulos, H. Tighiouart, D. E. Weiner et al., "Anemia as a risk factor for cardiovascular disease and all-cause mortality in diabetes: the impact of chronic kidney disease," Journal of the American Society of Nephrology, vol. 16, no. 11, pp. 3403-3410, 2005.

[56] J. M. Messana, C.-C. Chuang, M. Turenne et al., "Association of quarterly average achieved hematocrit with mortality in dialysis patients: a time-dependent comorbidity-adjusted model," American Journal of Kidney Diseases, vol. 53, no. 3, pp. 503-512, 2009.
[57] J. Rossert, C. Gassmann-Mayer, D. Frei, and W. McClellan, "Prevalence and predictors of epoetin hyporesponsiveness in chronic kidney disease patients," Nephrology Dialysis Transplantation, vol. 22, no. 3, pp. 794-800, 2007.

[58] J. M. López-Gómez, J. M. Portolés, and P. Aljama, “Factors that condition the response to erythropoietin in patients on hemodialysis and their relation to mortality," Kidney International Supplements, vol. 111, pp. S75-S81, 2008.

[59] A. T. Kausz, C. Solid, B. J. G. Pereira, A. J. Collins, and W. St. Peter, "Intractable anemia among hemodialysis patients: a sign of suboptimal management or a marker of disease?" American Journal of Kidney Diseases, vol. 45, no. 1, pp. 136-147, 2005.

[60] L. A. Szczech, H. X. Barnhart, J. K. Inrig et al., "Secondary analysis of the CHOIR trial epoetin- $\alpha$ dose and achieved hemoglobin outcomes," Kidney International, vol. 74, no. 6, pp. 791-798, 2008

[61] R. Minutolo, G. Conte, B. Cianciaruso et al., "Hyporesponsiveness to erythropoiesis-stimulating agents and renal survival in nondialysis CKD patients," Nephrology Dialysis Transplantation, vol. 27, no. 7, pp. 2880-2886, 2012.

[62] R. D. Kilpatrick, C. W. Critchlow, S. Fishbane et al., "Greater Epoetin alfa responsiveness is associated with improved survival in hemodialysis patients," Clinical Journal of the American Society of Nephrology, vol. 3, no. 4, pp. 1077-1083, 2008.

[63] A. Icardi, E. Paoletti, L. De Nicola et al., "Renal anaemia and EPO hyporesponsiveness associated with vitamin D deficiency: the potential role of inflammation," Nephrology Dialysis Transplantation, vol. 28, no. 7, pp. 1672-1679, 2013.

[64] J. J. Carrero, J. Axelsson, S. Snaedal-Jonsdottir et al., "Low hemoglobin in prevalent HD patients is associated with higher inflammatory status: impact of variations in the gene encoding for interleukin-6," in Proceedings of the American Society of Nephrology Congress, SA-PO30, 2006.

[65] T. Shinzato, K. Abe, A. Furusu et al., "Serum pro-hepcidin level and iron homeostasis in japanese dialysis patients with Erythropoietin (EPO)-resistant anemia," Medical Science Monitor, vol. 14, no. 9, pp. CR431-CR437, 2008.

[66] H. I. Feldman, S. Kobrin, and A. Wasserstein, "Hemodialysis vascular access morbidity," Journal of the American Society of Nephrology, vol. 7, no. 4, pp. 523-535, 1996.

[67] S. J. Schwab, "Vascular access for hemodialysis," Kidney International, vol. 55, no. 5, pp. 2078-2090, 1999.

[68] G. Grandaliano, A. Teutonico, A. Allegretti et al., "The role of hyperparathyroidism, erythropoietin therapy, and CMV infection in the failure of arteriovenous fistula in hemodialysis," Kidney International, vol. 64, no. 2, pp. 715-719, 2003. 


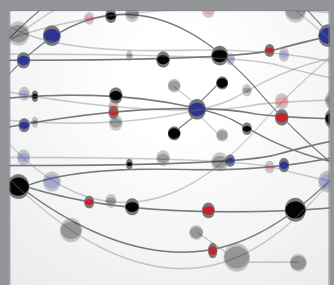

The Scientific World Journal
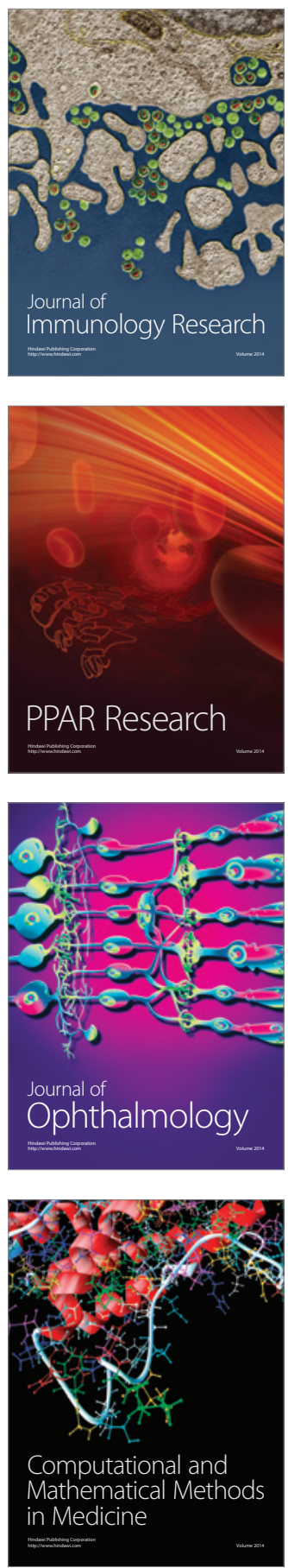

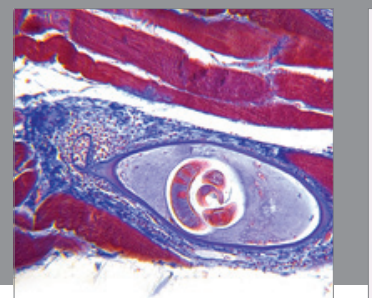

Gastroenterology

Research and Practice
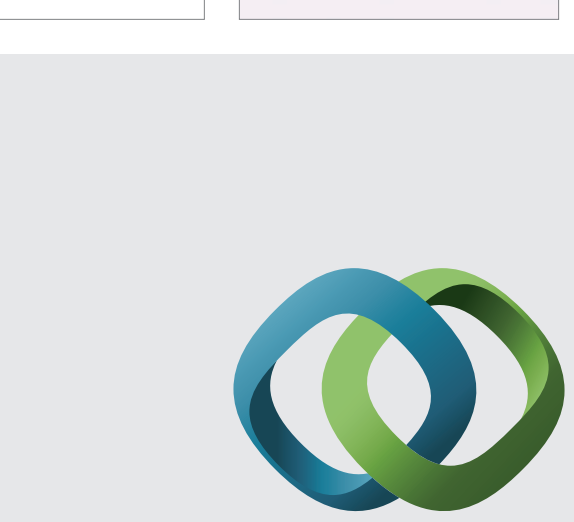

\section{Hindawi}

Submit your manuscripts at

http://www.hindawi.com
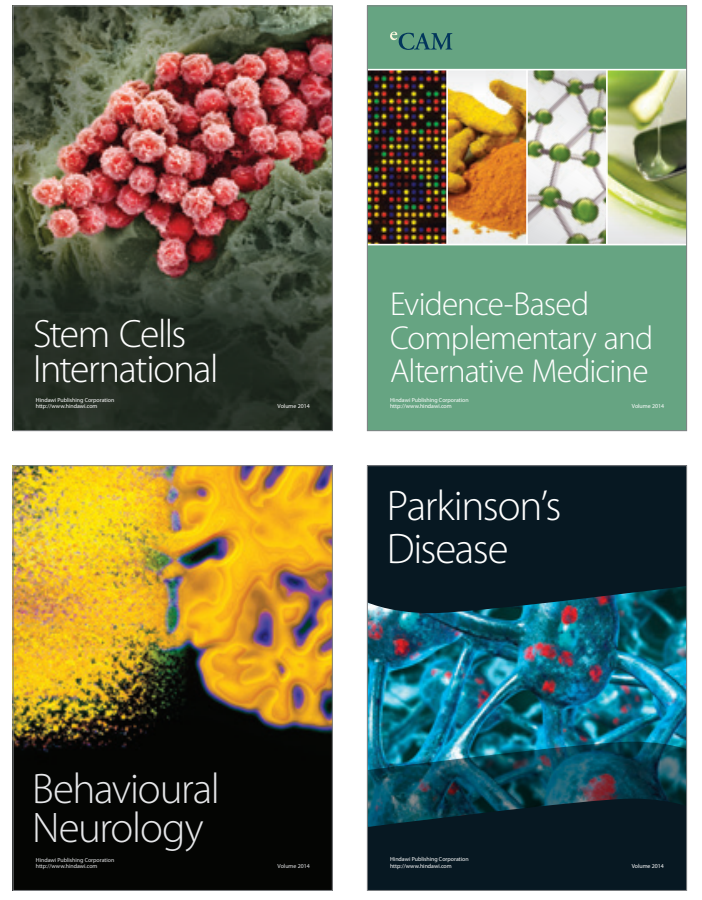
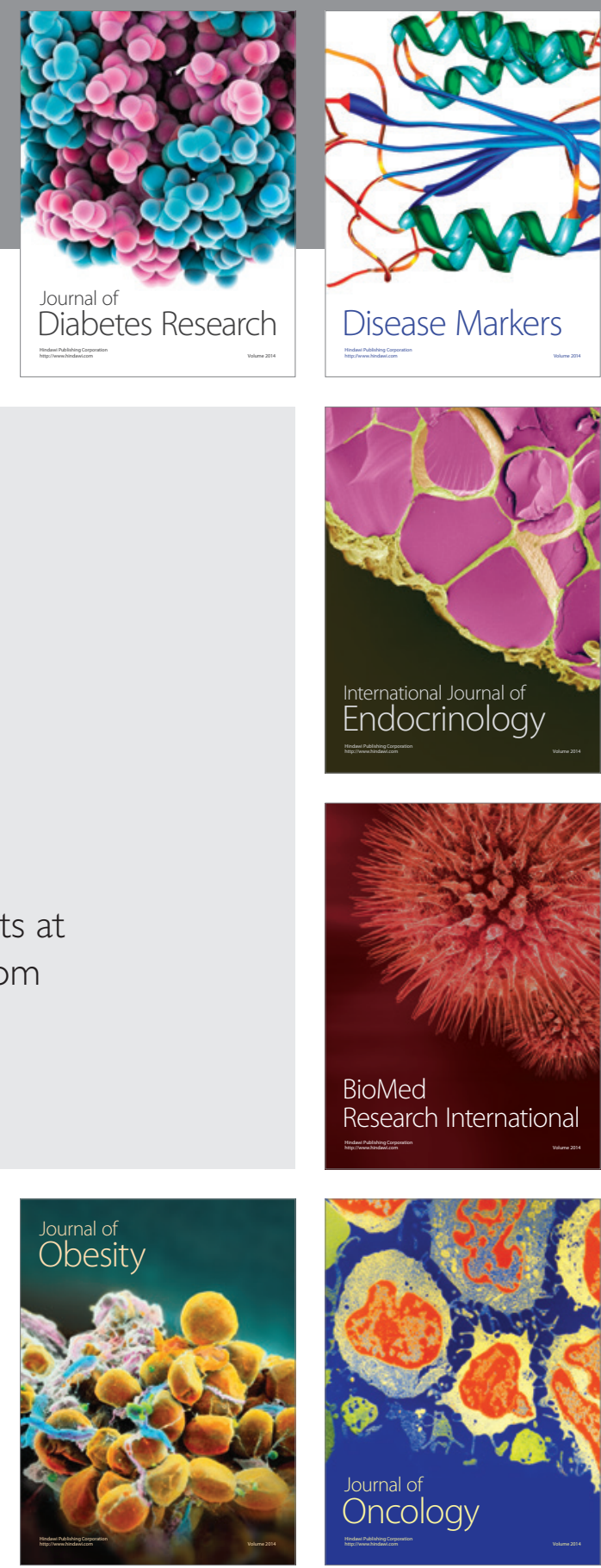

Disease Markers
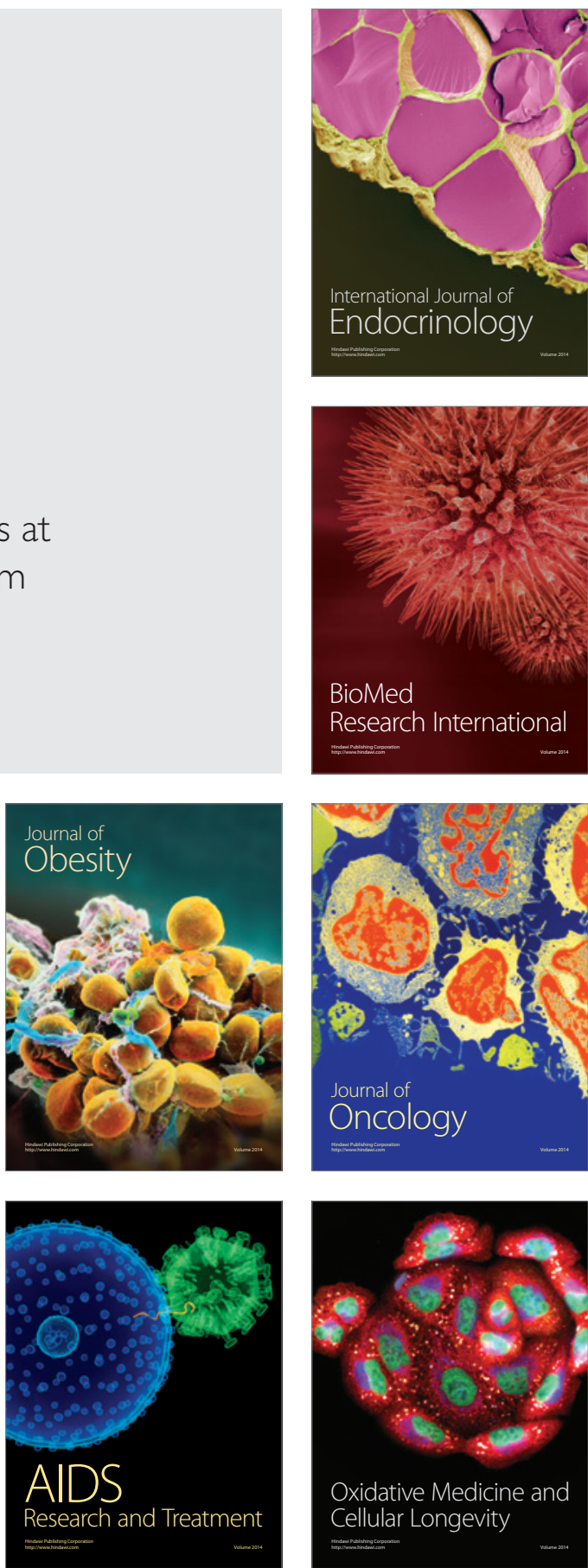